\title{
Understanding the distinctiveness of Chinese Post-80s tourists through an exploration of their formative experiences
}

\begin{abstract}
Chinese Post-80s (the Chinese equivalent of Generation Y) are a distinct generation that emerged during a period of rapid political, social and economic change under Deng Xiaoping's policy exploration with capitalism. Chinese Post-80s demonstrate higher levels of both complexity and sophistication in their tourist behaviours when compared with earlier generations of Chinese tourists yet their distinctiveness has been largely ignored in tourism research. Underpinned by generational cohort theory, this study explores the formative experiences of Chinese Post-80s and provides insights into the way these experiences have shaped this generation and their outbound travel. These formative experiences include Reform and Open Policy, One Child Policy and Education Reforms. Two discrete groups: "made in China" and transnational Chinese Post-80s tourists have been identified. We argue that while Chinese Post-80s tourists may share many aspects in common with their Western counterparts, this generation presents its distinctiveness due to its emergence from a specific sets of events with China's rapid change that make Chinese Post-80s different from any generation in the global environment, creating new academic inquiries for established theories of generational studies. This nuanced understanding of Chinese Post-80s tourists has profound implications for theory and practice in the context of Chinese outbound travel.

Keywords: Formative Experiences, Chinese Post-80s, Generation Y, Chinese Outbound Tourism, Bricolage
\end{abstract}




\section{Introduction}

In conjunction with the rapid growth of outbound Chinese tourism over the past decade there has been an increase in the number of scholarly publications about Chinese tourists. There is a consensus among both scholars and practitioners that the latest wave of Chinese tourists present new and distinctive tourism characteristics, behaviors, and forms (Wu \& Pearce, 2016) including shifting from package tours to independent travel (Jin \& Wang, 2016). Recently, a sub-group of Chinese tourists - Chinese Post-80s - have emerged as the key drivers of Chinese outbound tourism. This group is now claimed to account for roughly 56.2 per cent of outbound Chinese tourists (World Tourism Cities Federation, 2014). The Chinese Post-80s generation is approximately equivalent to the Western "Generation Y" in terms of the age group (Stanat, 2006). Growing up in the time of China's transformation, this group is characterised by "its optimism for the future, newfound excitement for consumerism, entrepreneurship, and acceptance of its historic role in transforming modern China into an economic superpower" (Jin et al., 2014, p. 618).

Chinese Post-80s tourists demonstrate significant differences from other tourist groups including the Japanese waves in the late 1980s and early 1990s (Breakey, Ding, \& Lee, 2008), previous generations of Chinese tourists (Prayag, Disegna, Cohen, \& Yan, 2015; Yang \& Lau, 2015) and their Western counterparts (Gardiner \& Kwek, 2017; King \& Gardiner, 2015). However, it is not clear why this group is distinctive and the broader social, cultural and political implications arising from this fast-growing market have not been explored. A close look at the extant publications on Chinese Post-80s reveals that current discourse in academic literature remains fragmented (Lian, 2014; Wei, 2009). A congruent knowledge of the concept is yet to develop. Indeed, tourism operators and destination managers are increasingly confronted by the challenge of aligning business practices and infrastructural provision (that 
predominantly cater to Western tourists) with Chinese Post-80s's needs to maintain their competiveness (King \& Gardiner, 2015).

The fragmented discourse surrounding Chinese Post-80s that currently exists in Western contexts is associated with, and reflective of, the discourse associated with this group in China itself. The rapid development of China in the last three decades has led to new manifestations of modernization that are, as yet, not fully conceptualized in either a cultural or a theoretical sense (Cockain, 2012). The image of Chinese Post-80s is heavily influenced by the Chinese media who have used their technical and ideological codes to construct a series of oversimplified yet contradictory narratives. First was the image of a "spoiled" and "selfish" generation courtesy of Chinese Post-80s' perceived heavy consumption behaviors and unique status within the family (Chen, 2008; Yang \& Lau, 2015). This representation created angst within Chinese society with the fear that this generation could not be relied upon to serve the wider community as their collective and harmonious parental generations had done (Cockain, 2012). Only in the last decade, Chinese society began to recognize and re-evaluate this generation (Rosen, 2009). The Chinese state newspaper - China Daily has a series of videos and a dedicated website about Chinese Post-80s (http://www.chinadaily.com.cn/video/focus/80s_index.html). As such a second narrative aligning Chinese Post-80s with "generosity" and "altruism" emerged in the wake of the 2008 Wenchuan Earthquake and the 2008 Beijing Olympics Games when this generation was heavily represented in media by images of volunteers assisting in times of need. Such contradictions in media representation are probably based on conceptual convenience approach (Cockain, 2012), which compares Chinese Post-80s with Westerners or/and their parental generation in a binary fashion. As Weber (2002, p. 352) states conceptual convenience produces "stereotypical and distorted constructions of complex, changing social realities." The sudden emergence of Chinese Post-80s has been too rapid for the public to develop a coherent 
understanding. Equally, the stark contrast that appears to exist between Post-80s and their parental generations brings into question previous understandings of Chinese behavior, particularly within the tourism context, and makes them untenable. This highlights the need for a study that synthesizes discourse around Chinese Post-80s and considers implications for tourism.

Within tourism in particular, a coherent understanding of Chinese Post-80s is urgently required as many destinations have now welcomed hundreds of thousands of these tourists. Generational cohort theory suggests that formative experiences during a generation's preadulthood define a group's basic perspectives and core values and that these will remain consistent throughout their life (Morton, 2002). As such, the purpose of this paper is to provide an analysis of the key formative experiences of Chinese Post-80s in order to offer initial insights into their tourism behaviours and to identify future research needs to develop a deeper understanding of the role they will play in $21^{\text {st }}$ century tourism.

This paper commences with its theoretical underpinning - generational cohort theory. A discussion of the concept of Chinese Post-80s and their formative experiences follows. The distinctiveness of the Chinese Post-80s generation in tourism and ways in which they view the world are examined. The article concludes with both theoretical and practical implications for scholars and practitioners.

\section{Theoretical background in approaching a generation}

Generational studies have a strong basis in sociology and gained prominence in management and business fields with the recognition of the usefulness of segmenting generations as a technique to understand a group's values and preferences. The standard approach categorized Western society (mainly Australia, UK and USA) into four generations -Veteran, Baby Boomer, Generation X and Generation Y (Parry \& Urwin, 2011; Strauss \& Howe, 1991). In the mainland Chinese context, there exist four similar generations but with different age 
brackets - Republican, Consolidation, Cultural Revolution, and Post-80s (Social Reform) generations (Egri \& Ralston, 2004). The various generations are categorized according to significant historical events during their pre-adulthood (the formative years) that influenced their values (Chung, Chen, \& Lin, 2015). A critical appreciation of the formative years of a generation has many uses. For instance, marketing practitioners often draw on the nostalgia of a particular generation's formative years for effective marketing, including the use of celebrities and/or film stars that "belong" to a generation for compelling marketing campaigns (Parry \& Urwin, 2011).

In order to examine a particular generation and its dynamics it is essential to understand the formative experiences that shaped the generation and to make sense of these experiences in the broader discourse and contexts within which the generation formed (Steele, 2012; Wyn \& Woodman, 2006). Generational cohort theory provides a useful and ideal theoretical lens as it posits that individuals from a particular generational cohort share a distinctive set of macrolevel economic, social and political events from their impressionable pre-adult years (Strauss $\&$ Howe, 1991). The events of their formative years bind people from a particular generation together to create generational cohorts and these events have a lasting impact on the generation (Strauss \& Howe, 1991). The resulting values and beliefs remain stable throughout a generation's different life stages (Inglehart, 1997; Morton, 2002; Strauss \& Howe, 1991).

According to Chung et al. (2015), generational cohort theory is different from life stage theory, which posits that an individual's values, beliefs and behaviours change throughout their life cycle, suggesting that all individuals within a culture will pass through the same stages throughout their life and that there is consistency of values from generation to generation (Chung et al., 2015; Erikson, 1998). From a life stage theory perspective, younger generations will have similar values to older generations, shifting in similar ways as they reach each life stage (Parry \& Urwin, 2011). However, evidence from longitudinal studies confirms that the 
values developed in the context of the social-economic conditions of one's pre-adulthood remain stable throughout life (Egri \& Ralston, 2004). Aberrations may occur in times of social upheaval but these changes are usually "only temporary shifts with generations' value orientations returning to previous levels once stability is regained" (Egri \& Ralston, 2004, p. 211). Therefore generational cohort theory provides a more effective lens to understand a generation's value systems and behaviours (Chung et al., 2015).

In addition, generational cohort theory posits that when a significant change occurs in a society during a generation's formative years, it will result in a more distinctive generation. Chinese Post-80s' formative years were situated in a period of rapid and significant change as China embraced Deng Xiaoping's modern reform and open policies (Chung et al., 2015). Ryan et al. (2016) highlight that intergenerational differences in China are likely to be greater than in many other countries requiring future research in this area.

Generations form their values in their formative years and "reflect the value priorities emphasized during a country's particular historical period” (Egri \& Ralston, 2004, p. 210). For Chinese Post-80s this historical period encapsulated considerable social change. It is likely that the values adopted by this generation during their formative years will be both distinctive and stable throughout their lifespan. It is of both theoretical and practical importance to understand this generation because as they become the majority in Chinese society and the members of this generation assume social positions of power and influence, their value orientation will become dominant (Inglehart, 1997).

The generational cohort theory lens undertaken in this study resonates with a famous Chinese saying about "branches and their blooms: sometimes flowers may confuse people and make them neglect the existence of branches on which they thrive" (Li, 2015, p. 137). Thus, this conceptual paper concentrates on the branches and even the roots of the blooms known as Chinese Post-80s. 


\section{Concept of Chinese Post-80s (baling hou八需局)}

The famous Chinese writer Gong Xiaobing first introduced the concept of Chinese Post-80s to describe a group of writers born after 1980 in his article "Summary of Post-80s" published on the Chinese Tianya online forum in 2003. Typical representatives of this group are Han Han with his Triple Gate book (2009) and Guo Jingming with his Never Flowers in Never Dreams book (2008). Their work reflects the values of this generation including their discontent with the conventions of life, love and education. Time Magazine named Han Han as one of the most influential people of 2009 and in $2010 \mathrm{CNN}$ described him as the rebel voice of his generation (CNN 2016). The success of writers such as Han Han and Guo Jingming at an early age (both had earned celebrity status by their early 20s) has fundamentally changed the view of the traditional path to success in Chinese society. They represent a new cultural symbol of their generation; a symbol of the transformation taking place in China (Wei, 2009).

Chinese Post-80s were born between 1980 and 1995 and are the first products of China's One Child policy (Stanat, 2006). At the time of this research, they are aged between 20 and 36 years old and range from university students to junior or middle level employees in China. They represent a population of around 340 million (National Bureau of Statistics China, 2010). Various sources suggest that this generation is the main driving force of China's future consumption, including tourism, as well as the backbone of many enterprises (China Daily, 2010; Gu, Wang, Sun, \& Xu, 2010; Renesas, 2013).

\section{Formative Experiences of Chinese Post-80s}

Because of their distinctive formative experiences, Chinese Post-80s demonstrate significant differences from their parents in terms of values, behavior, lifestyle and political participation (F. Liu, 2011; Wei, 2009). Although there is no conclusive definition on what formative experiences are, scholars tend to treat the period from the onset of puberty to young adulthood as an individual's formative years, as this period presents a time where a person experiences 
psychosocial development (e.g. search for their own identity)(Gardiner, 2011). More importantly, this period presents a time when an individual reflects on the values from society and their parents so as to establish their identity (Berger, 2008). To be qualified as a formative experience, an event that influences a generation, has to be major, macro or cataclysmic, disrupt the foundations of a society's existing system, and occur during one's formative years (Gardiner, 2011; Wuest, Welkey, Mogab, \& Nicolas, 2008). Thus, based on this reasoning, three public policy reforms of the late twentieth century were significant in shaping the experiences of the post-80s generation in their pre-adult years: Reform and Open Policy, One Child Policy, and Education Reforms (Gardiner \& Kwek, 2017; Lian, 2014; Wei, 2009). These events with their wide implementation across China have fundamentally disrupted the previous societal system of China. To understand more about this generation, it is necessary to examine each of these reforms and the ways in which they have shaped this cohort.

\section{Reform and Open policy with Deng Xiaoping's exploration of capitalism}

In 1978, with Deng Xiaoping's return to power in the Central Committee of the Communist Party of China, China implemented economic reforms which included opening up the country to foreign investment. Since then, China has undergone extraordinary institutional changes, including market liberalization and restructure of state owned enterprises that has resulted in economic growth and enhanced well-being for the Chinese people by greatly improving the material living standards of many Chinese families (Lian, 2014).

Because of these reforms the Post-80s generation did not experience the same levels of poverty that previous generations had during China's Great Leap Forward Movement (19581961) and the Cultural Revolution (1966-1976). Their experiences started from the beginning of China's period of rapid modernization and many enjoyed the material comforts of modern consumer lifestyles. This resulted in conceptual and attitudinal differences from their parents towards consumption (Lian, 2014). As a result of growing up in a consumption-driven society, 
Post-80s tend to be more active and demanding in their consumption, whereas their parents continue to value hard work and treat thrift as a virtue (Wei, 2009). However, it should be noted that the patterns of inter-generational mixing have been taking place in China. With the expansion of higher education and emphasis on education from Chinese parents, intergenerational interaction has arguably reduced, as earlier young people went out to work at earlier ages and so mixed in "adult' society much more than today. Thus, parental life styles, to a large degree, could have a longer influence on Chinese Post-80s.

Consumer culture for Post-80s is a direct result of the Reform and Open policy which exposed this generation to not only greater wealth but also Western ideologies and practices around consumerism. Western literature on consumer culture is substantial (Featherstone, 2007); however, consumer culture in Chinese and Western contexts are disparate (Hulme, 2014). For example, the Chinese government has been influential in shaping consumer culture and, arguably, wields a heavier hand than most Western governments; particularly in the areas of endorsing, banning and taxing various imported goods (Hulme, 2014). Additionally, classical Chinese philosophical views (such as Daoism) continue to mediate the rise of materialist aspects of consumerism (Sigurðsson, 2014). While Chinese Post-80s are generally perceived to enjoy consumption by building their sense of self, they also express concerns or even dissatisfaction with the commercialization of their living spaces and being surrounded by domestic-based leisure commodities (e.g. televisions, Taobao Shopping) (Cockain, 2012). Some of them even propose a "quiet" and "back to origin" life as a means to escape from the oppression of consumer culture, such as their increasing participation in outdoor adventure tourism.

With a market economy replacing a planned economy, social competition intensified in China. Post-80s grew up in a time in which the fittest survives and thrives and this played an important role in constructing their belief system ( $\mathrm{Li}, 2015)$. While economic development 
provided Chinese Post-80s with greater opportunities for enhanced lifestyles, the competitive environment placed constraints on their choices (Li, 2015). Chinese Post-80s entered a period in Chinese history where the opportunities for social mobility were unprecedented; yet the rapid change also brought a sense of confusion and alienation as traditional ways of being are annihilated and cultural identity becomes blurred and ambiguous (Li, 2015; P. Zhang, 2009).

It should be noted that the affluence brought about by the Reform and Open Policy is related to geography. Rapid modernization and urbanization occurred primarily in the cities which, together with the Hukou policy (household registration system), meant that Post-80s living in cities, particularly first-tier ones, had access to more material and education resources than those from rural areas $(\mathrm{Li}, 2014)$. Therefore caution should be used to differentiate Chinese Post-80s according to regional identities.

The Reform and Open Policy provided many Chinese Post-80s with unprecedented opportunities for travel outside China with the Chinese government recognizing tourism as an economic activity as well as an opportunity for leisure for its citizens and establishing Approved Destination Status (ADS) agreements with many countries to allow self-funded Chinese tourists to travel for pleasure (G. Zhang, 2015). Many destinations have liberalized their visa policy for Chinese tourists in the hope of increasing visitation from what is now regarded as a lucrative market (G. Zhang, 2015). As such, Chinese Post-80s are the first generation to take advantage of these opportunities for independent travel and freely explore destinations outside China.

\section{One Child Policy}

At the same time that China was implementing its economic reform, the One Child Policy was put into effect. The One Child Policy was a unique family planning policy in China that was promulgated in 1979 and widely implemented in 1980 across China following the passing of China's second Marriage Law (D. Liu, 2015). The purpose of this family planning policy was 
to control the explosive population growth in China and as a result significantly restructured the traditional Chinese family from a model where 4-6 siblings was common to the "4-2-1" structure (i.e. four grandparents, two-parents and one child) (Riley, 2004).

Having no siblings, Chinese Post-80s spent their childhood mainly with adults or stayed alone at home (Lian, 2014) and the traditional component of Chinese family education of interaction with siblings diminished (Lian, 2014; Jingyan Liu et al., 2014; Sabet, 2011). This traditional sibling relationship in China was highly valued as a key element of adult social networks that maintain gifts and favours, and was considered vital to economic and emotional well-being (Fong, 2007). Chinese Post-80s parents have attempted to make up for this lack of sibling relationships by educating their children to be sociable with friends in order to maintain renqing (human feelings) and guanxi (connections) (Fong, 2007). Post-80s extended their relations outside of the family to society and, subsequently, their development has been heavily influenced by societal influences such as their formal school education than was the case for previous generations (Jingyan Liu et al., 2014).

The One Child Policy has made Chinese Post-80s heavily reliant on, and influenced by, social trends and more likely than their parents, and arguably even their Western counterparts, to seek information from social media and to trust the opinions of their peers ( $\mathrm{Wu} \&$ Pearce, 2016). Consequently, social media is central to the lived experience of most Chinese Post-80s and has become their point of reference for all stages of their travel (Wu \& Pearce, 2016). For example, both qyer.com and mafengwo.com (two Chinese blog websites with many thousands of blogs from this generation) are referred to by Post-80s as their little lonely planet.

The One Child Policy resulted in Chinese Post-80s receiving excessive attention from their family. As such, they have been portrayed as little emperors in the family and are generally perceived to be less caring towards others than their parental generations (Wei, 2009). Improved living standards combined with fewer offspring has resulted in Chinese Post-80s 
being better educated and more affluent than previous generations (F. Liu, 2011) and are inclined to spend more money on themselves than their parents spend on themselves (Cao, 2009). This consumption behavior is largely due to their optimistic attitude toward China's economic development, and undivided attention from their parents, making them feel financially secure and entitled. However, this might be less true today, as the older members themselves have been parents with increasing responsibilities. In particular, Chinese Post-80s are experiencing a time of the rapid rise of property prices.

As a result of improvements in living standards, their pursuit of a better quality of life, extensive and exclusive attention from their parents, and no experience with extreme poverty, Post-80s tend to be more individualistic and self-centred, and think and act independently (Wei, 2009). In terms of their consumption motives and preferences they favour hedonistic values (e.g. novelty seeking) more than utilitarian values (e.g. quality) (Hsu \& Huang, 2016; C.-L. Wang, Chen, Chan, \& Zheng, 2000). In particular, they seek add-on experiential components of products to maximize their personal travel experience.

The Chinese phrase "Zhong Zai Can Yu" (participation is more important than anything else) has become a mantra for Chinese Post-80s. When they travel, they demand interactive and adventurous activities that reflect who they are. For them, participating in an adventure tourism activity goes beyond the activity itself. It is about their identity. Buckley, McDonald, Duan, Sun, and Chen (2014) estimate that around a quarter of Chinese Post-80s have purchased at least one of the seven piaoliu (adventure tourism activities) products in China. More importantly they look for experiences that help differentiate them from their peers (Cockain, 2012). This explains why they might stay in a youth hostel, but they are very willing to pay for costly activities such as sky diving. This spending pattern may represent a point of difference between Chinese Post-80s tourists and Western backpackers (King \& Gardiner, 2015). 
Paradoxically, along with their interest in adventure tourism, Chinese Post-80s are concerned with safety and value restraint, balance and moderation. They have the obligation to fulfil their Xiao (filial piety) (Gardiner \& Kwek, 2017) which includes some level of adherence to the value of Zhongyong. The notion of Zhongyong is a propensity for the middle point between extreme choices. The moral code of Zhongyong primes Chinese people to take a moderate attitude towards everything and to avoid taking a prominent position or going to extremes. Because of their parents' support and their expanded freedom to explore, traditional values such as Zhongyong have less impact on Post-80s but they still exist. As such, they exhibit caution and tend to travel in small groups rather than alone, particularly when they are "strangers in the strange land" (King \& Gardiner, 2015).

\section{Education reforms}

The third great reform that served to modernize China in the late twentieth century was a series of education reforms. Ryder (1965) argues that in a modern society, secondary socialization is more salient than primary socialization in the creation of a generation. Secondary socialization describes people's processes of learning the appropriate behavior as a member of a society. This process occurs from late childhood to pre-adulthood enabling human beings to learn the norms, values and roles of the culture (Ryder, 1965). Secondary socialization is largely attributed to the education system (Ryder, 1965).

Two major education reforms were enforced in the Chinese education system that significantly impacted Chinese Post-80s. The first was the implementation of nine-year compulsory education in 1986 . This reform greatly increased the literacy rate of many Chinese Post-80s, with many acquiring at least a university-preparatory type education, compared to their parental generation, many of whom barely completed primary education (Lian, 2014). The other significant change stems from China's former president Jiang Zemin's development strategy regarding science, technology and education. Large government investments devoted 
to developing key universities in China allowed them to develop relationships with other universities, communities and industry, domestically and internationally, without rigid control from the government, as well as to raise funds and form their own strategies (Guthrie, 2012). This resulted in improvements in facilities and allowed Chinese Post-80s to access greater education resources including study abroad opportunities (Li, 2015).

In addition to the educational impacts arising at these macro policy reform levels, China has undertaken school curriculum reforms (Rosen, 2009). Chinese traditional cultural values were restored to the curriculum and re-emphasized in schools; the Cultural Revolution (19661976) had previously attempted to purge these. Chinese Post-80s were formally taught Chinese traditional Confucian values at school, such as Ren and Xiao (benevolence and filial piety) (Cao, 2009). Their education was also steeped in Chinese literature, including poetry, and this has influenced the way they appreciate landscapes. When they travel to certain places, literature learned at school provides them with emotional connections. This is why many Chinese Post-80s use poems to articulate their experience and feelings towards a destination. When they gaze at a landscape they are renowned for "zooming in for a finer gaze and zooming out for a further gaze and imaginary overlook [...enabling them to] reflect on past events and life in general and to arouse an appreciation of this historical continuity or changes beyond the immediate scene" (Yu \& Xu, 2016, p. 402).

Western literature and values were introduced into the formal school curriculum, albeit not intensively. This helped Chinese Post-80s to develop an understanding of the Western world and developed cultures that may have been missing in previous generations. At the same time the Chinese government embedded their own political ideology in the education system, which included a patriotic discourse with the emphasis on China's past national humiliations, in order to foster love of the nation (Z. Wang, 2008). Cheng and Wong (2014) confirm that Chinese Post-80s are influenced by Chinese political ideology including nationalism. This was 
made apparent in their travel decisions during the period of China and Japan's island dispute. However, it is unclear how, and to what extent, this will be manifested in other contexts. Indeed, the question as to the ways in which Chinese traditional values, Western values, and Chinese political ideology manifest in Chinese Post-80s travel experiences remains largely unexplored.

Through their education reforms the Chinese government de-emphasized class struggle and socialist ideology and engineered a greater focus on economics, science, technology and global trends that were pragmatic to maintaining its legitimacy; shifting the government "from a legitimacy based on ideological criteria to a legitimacy based on performance indicators" (Rosen, 2009, p. 366). This performance oriented approach (which included, for example, unified college entry exams) has resulted in a more pragmatic and success-oriented Chinese Post-80s; "their public lives are placed in service to their private ambitions" (Rosen, 2009, p. 368). These reforms provided Chinese Post-80s with opportunities to enrich their knowledge, broaden their horizons and establish their distinct values.

Outcomes of the education reforms have been mixed for Chinese Post-80s. On the one hand they enjoy the position of decision makers in their families and wield significant influence about the travel decisions of their parents and family members (Wei, 2009). This is due largely to the fact that their parental generation trust their advice based on the perception that Chinese Post-80s are better educated and have a greater ability to seek out and obtain valuable information to make informed decisions. On the other hand, the mass education reforms have intensified both expectations and competition for benefits such as good employment opportunities and high standards of living and this has created discontent with the emergence of a gap between expectations and reality (Rosen, 2009). 


\section{Diversification of social and cultural values}

Together, China's Open and Reform Policy, One Child Policy and Education Reforms led to the diversification of the cultural structure of Chinese society which intensified in the early 1990s as the Post-80s generation was growing up (Wei, 2009). Their formative years occurred at a time when state-sanctioned attitudes towards Western values changed from something that needed to be resisted to something that was deemed appropriate in Chinese society. At the same time, Chinese traditional cultural values were restored after being banned during the Cultural Revolution and their importance was re-emphasized in the societal system. Evidence shows that the enduring influence of Chinese traditional values remains strong (Lin, 2011; Pan, Rowney, \& Peterson, 2012). Consequently while Chinese Post-80s seek freedom and individualism, they still adhere to traditional social responsibilities such as taking care of the older generation (James Liu, Li, \& Yue, 2010), but with their own modified versions of how this is done. While it is important to pay Xiao, there are different ways to achieve it. Meanwhile, as a socialist and communist country, the Chinese government has ensured that their political ideology continues to permeate everyday life in Chinese society. However, none of these values have been able to fully dominate the Post-80s generation. While Chinese Post-80s are more open-minded to this suite of values, they also enjoy critiquing them (Rosen, 2009).

In summary, the economic boom in China, the One Child Policy, and exposure to western values through the economic and education reforms that coincided with the formative years of Chinese Post-80s have provided this generation with abundant opportunities to explore change, enjoy diversified choices, and bring their personalities into full play. But the Chinese socialist ideology and Chinese traditional values still colour their perceptions and values; albeit with the Post-80s' own interpretation and adaptation. These major changes have led to the Post-80s generation in China to live a life that bears little resemblance to their parental generation. Thus, their own unique value systems have emerged and form an essential foundation that has influenced Post-80s to develop a clearer sense of their own rights and 
entitlement, and to pursue their self-identify and self-expression (Yan, 2010) with ongoing influences from Chinese socialist ideology and traditional values. The combination of the three value sets present a conflicted model and Chinese Post-80s are constantly discovering new ways of resolving these tensions (Palmer, 2012).

\section{Conceptual Framework of Chinese Post-80s}

To illustrate the formative experiences of Chinese Post-80s and various relationships described earlier, an explanatory model (Figure 1) was established. In Figure 1, the center of the circle on the left represents Chinese Post-80s. The inner circle comprises their formative experiences including One Child policy, Reform and Open policy and education reforms. Each of their formative experiences intertwines with each other. For example, because of Open and Reform policy, the Chinese government has allowed Western materials into the Chinese education system while also reinforcing Chinese traditional values. The outer circle represents diversity of values in contemporary China as a result of the One Child policy, education reforms and Reform and Open policy that have penetrated Chinese society. These result in a distinctive triple-value system for Chinese Post-80s, which influences their identities, characteristics, attitude and behaviors, and their experiences. This triple-value system is a mixture of Chinese traditional, Western values and Chinese political ideology with Chinese Post-80s' own modification.

Each generation has its own collective experience around particular reference points. Their experience is internalized during their formative years (pre-adulthood) and drawn upon to formulate distinctive worldviews. Roskin (2012) argues that the interpretations of generations rely on how things are filtered through a generation's own lens and Steele (2012) further adds that across generations, contemporary events are experienced through past, recalled events; a past re-experienced in the present to create the normative, moral and rational base for action. Hence, when Post-80s approach the world outside China, they zoom in on the particular tourism 
context with a Chinese gaze developed by their formative experiences and values and zoom out with new learnings that they pragmatically draw into their past experience with present and this process underpins their behaviour (right side of Figure 1). However, their processes of zooming in and zooming out are moderated by a convenient and pragmatic view.

In constructing a convenient view (middle of Figure 1), G. Kelly (2003) personal construct theory is relevant. People approach the world through their own socially influenced and personally cultivated views and these views have a range of convenience (G. A. Kelly, 1977). Hence, Chinese Post-80s' perception of the world depends on the current situation, who they are with, and in what role (Procter, 2009) (i.e. advanced culture, culturally similar or distant destinations).

Co-existing with the convenient view is the pragmatic view that has dominated the thinking of Chinese people since the 1980s (Zhao, 2000), and is particularly strong with Chinese Post-80s (Rosen, 2009). This is demonstrated by China's pragmatist leader, Deng Xiaoping's famous saying "It doesn't matter if a cat is black or white, so long as it catches mice". This saying reflects China's strategy of modernization by taking any pragmatic policies shown to be correct for China's rapid growth. As such, for Chinese Post-80s, they will first zoom in to recognise the situation they are in and then zoom out to relate this to themselves at an individual level using a pragmatic approach by choosing the means that are relevant and beneficial to them. In this respect, we refer to Chinese Post-80s as bricolage as they understand and combine readily available information to discover and grab fresh or expanded mental representation (Boxenbaum \& Rouleau, 2011; Lévi-Strauss, 1966). Being pragmatic, they integrate existing values and remodify them rather than inventing a new value. Adopting pragmatic and convenient approaches in gazing at the world, Chinese Post-80s utilise a distinct way of operating their complex value system, combining different values in response to contextual factors. 


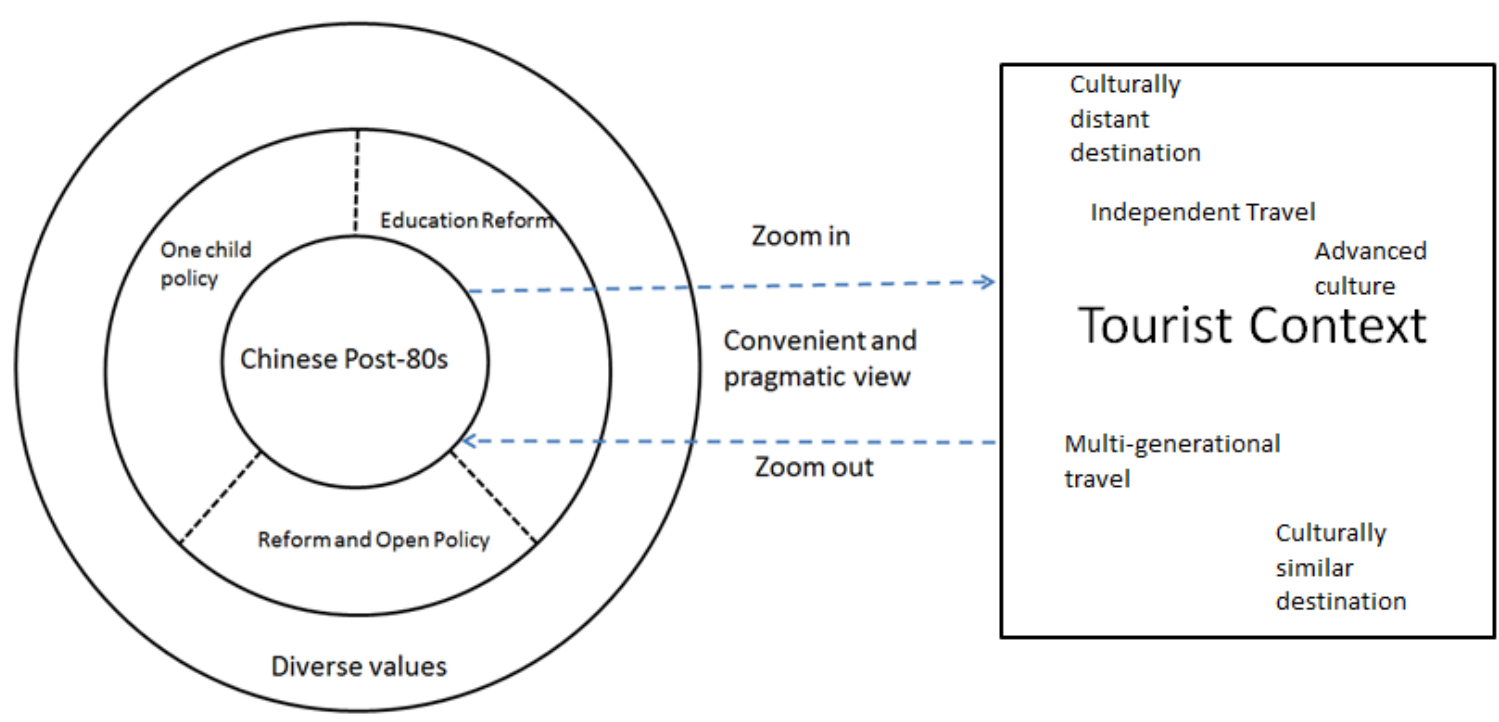

Figure 1: Post-80s' value system operating in a tourism context

\section{Chinese Post-80s tourism research}

In tourism, evidence is emerging of the influence of Chinese Post-80s' formative experiences on their outbound travel behaviour. A study by Chung et al. (2015) on generational cohorts in Taiwan and mainland China argues that mainland Chinese tourists' motivation to visit Taiwan is strongly influenced by their personal values developed in their generation cohort and that these values influence both their behavioural intention and actual behaviour. In a similar study, Jin, Lin and Hung (2014) found that Post-80s' expectations of outbound group tours were shaped by cultural values developed in Chinese Post-80s' pre-adulthood which influenced the perceived importance attached to service attributes. A closer examination of the relevant research concerning Chinese Post-80s tourists reveal that current studies tend to: 1) focus primarily Chinese Post-80s' tourist experience within mainland China (Wen, Lehto, Sydnor, \& Tang, 2014) or nearby regions (Ong \& du Cros, 2012); 2) study Chinese international student groups (Gardiner \& Kwek, 2017; King \& Gardiner, 2015); 3) focus on Chinese independent tourists generally who might not be necessarily be representative of Chinese Post80s (Wu \& Pearce, 2014); and 4) use a quantitative approach and adopt existing Western constructs (T. Jin et al., 2014; Yang \& Lau, 2015). While many of these studies offer a 
descriptive analysis of a particular aspect of this generation, they tend to lack depth, partly due to a failure to demonstrate an understanding of the formative experiences which have shaped the attitudes and values that contribute to their current tourist experience (Lian, 2014). Yang and Lau (2015) cautiously point out that most of the existing literature on generation analysis is not applicable to the emerging regions and call for novel approaches when investigating Chinese Post-80s. Only recently, through the investigation of Chinese international students participating in adventure tourism, Gardiner and Kwek (2017) have started to provide a more insightful view of Chinese Post-80s by linking tourist experience to Chinese Post-80s' formative experiences.

An integrated perspective that takes Post 80 s' formative experiences into consideration is needed to understand their outbound travel, including their motivations, social behaviours, sensory, cognitive and affective components of their experience and the driving forces behind them. Post 80s have expanded their itineraries from travel to nearby regions (Macao and Hong Kong) to other Asian destinations, and more recently to long haul, non-Asian destinations, and their confidence and experience is evolving. However, many Chinese Post-80s tourists are the first in their family to explore destinations outside of China. With limited information from their parents and peers, their formative experiences, as well as their domestic travel experiences, play a crucial role in shaping their expectations of the outside world, including destinations which are culturally dissimilar (Buckley et al, 2014).

Further to recognizing the distinct formative experiences of Chinese Post-80s, it is also useful for us as researchers to recognize the variations within this generation. Chinese Post-80s can be broken down into two discrete groups: "made in China" Post-80s and transnational Chinese Post-80s. While both groups share their common formative experiences, each of them presents their own distinctiveness. 


\section{Made in China Post-80s}

Made in China Post-80s tourists currently account for the largest proportion of this group (China Tourism Academy, 2014). The term describes Chinese Post-80s who have spent their entire study in China and are currently working in China. This group has relatively limited first-hand experience with other cultures. Within this group, those from first-tier cities are more exposed to rapid changes than those from second tiers cities while those from second and third tiers cities rely more on online services due to limited access to face-to-face tour operators; they also have fewer resources in terms of experienced friends and family members to draw on for travel information (China Tourism Academy, 2014; World Tourism Cities Federation, 2014). "Made in China" Post-80s generally rely on popular media for immediate and wide knowledge of the rest of the world.

\section{Transnational Chinese Post-80s}

Transnational Chinese Post-80s refers to who have studied or are currently studying overseas and whose lives, interests and connections are based in multiple countries, as international education has a transformative effect on people's behaviour (King \& Gardiner, 2015). This group have become "intercultural mediators who learn to grow beyond the psychological parameters of their own origin culture" (Brown, 2009, p. 184). The result is the enhancement of their self-efficacy (Milstein, 2005), intercultural confidence and expanded outlook of the world (King \& Gardiner, 2015). As such, they are more willing to take extra efforts to visit off the beaten track destinations and are skilled in obtaining various sources of information without heavily relying on their relatives and friends.

\section{Conclusion}

Recent years have witnessed a surge in outbound Chinese tourists driven by Chinese Post-80s. They are currently the largest driving force for Chinese outbound travel and it is widely predicted that their number will increase significantly over the next five to ten years. They are 
changing the landscape of Chinese outbound tourism. Yet, to date, Chinese Post-80s have received only modest academic attention in general, and particularly in tourism where studies remain isolated and limited in scope. While the intent of this paper is not to provide suggestions or solutions to the challenges for tourism scholars or practitioners arising from this generation, it does suggest that much of the literature on tourism continues to follow the trend of a simplified shift from Anglo-Western centrism to a "one size fits all" Chinese centrism approach, resulting in attention being given principally to a prototypical, simplified and homogenized tourist subject (Winter, 2009). This paper highlights other layers of complexity to be considered when approaching Chinese Post-80s tourists. Indeed, while Chinese Post-80s may share many aspects in common with their Western counterparts, this generation in fact presents its distinctiveness due to its emergence from a specific sets of events with China's rapid change that make Chinese Post-80s different from any generation in the global environment, creating new academic inquiries for established theories of generational studies (Hulme, 2014). We have provided a deeper understanding of Chinese Post-80s by establishing a conceptual model to explain their various aspects, which invites further theoretical challenge and critique. The ongoing rise of Post-80s tourists promises to redefine the way we think, approach and sustain a research agenda that demands novel theoretical and methodological approaches. Therefore, by providing a clear and rich understanding of the formative experiences of Chinese Post-80s, new research directions have become clearer. Table 1 highlights a number of future research areas of Chinese Post-80s tourists.

Table 1: Future Research Directions
Findings from existing
Possible future research directions in tourism literature 
- Mixed influence of traditional values, Western values and socialist ideologies on Chinese Post-80s during their formative experiences. Chinese Post-80s gaze is developed through an evolving blend of different cultural values.

- Isolated approach - without the consideration of Chinese Post80 s' formative experiences when investigating their outbound travel experience may lead to misinterpretation

- Many Chinese Post-80s are the first generation to travel outside China freely and independently.
- In which way do Chinese Post-80s demonstrate similarities and differences from other generations in China as well as their Western counterparts in terms of their outbound travel experience?

- What differences exist within Chinese Post-80s generation, and what factors contribute to these as well as how these influence their outbound travel, such as madein-China and transnational Chinese Post-80s?

- How do Chinese Post-80s experience "otherness" and what underpins their perception of "otherness"?

- How do Chinese Post-80s construct "Self" through their outbound travel?

- How do Chinese Post-80s negotiate with their peers when there are points of disagreement and resolution during their outbound travel? What are their negotiation strategies?

- How Chinese Post-80s' cultural exchange and interaction with others during their travel influence their tourist behavior back home?
- Emerging evidence on differences between Chinese Post-80s and other generations in China/Western counterparts but not extensive

- Chinese traditional values can still remain strong for Chinese Post-80s; however, culture being a determinant for Chinese Post-80s is questionable
- When and in which context do the values of Chinese Post-80s activate? For example, Chinese Post-80s can still be collective but in which context do they demonstrate collectivism?

- How important do family ties, respect of authority, Xiao (filial piety), and Guanxi influence their travel decision?
- Differences between China and the West in terms of technology advancement, social media empowerment and political influence over internet.
- How do Chines Post-80s use social media in their outbound travel decision-making process? How different will these be from their Western counterparts?

- What's Chinese Post-80s' cultural orientation towards social media marketing and mobile App use?

We argue that the intricacies of the value systems underpinning the behaviours and attitudes, expectations and motivations of Chinese Post-80s tourists can be better understood with reference to generational cohort theory and the complex and dynamic formative experiences of this generation. As Li (2015) suggests, understanding Chinese Post-80s starts from " their most personal experiences as they grew up, to the present self in relation to the social-cultural contexts that have shaped their identities, evoking emotions and revealing their struggles and confusions in life as well as their despair and hope towards the future for 
themselves and Chinese society" (p.137). This research is a starting point for our scholars and practitioners to reflect on the emergence of Chinese Post-80s in a tourism context and we invite future discussion on how we could better respond to this generation. Here we have presented a small step for this larger endeavour in revealing the complexity of Chinese Post-80s.

\section{Acknowledgement}

The author would like to express his great appreciation to Associate Professor Deborah Edwards and Dr Xin Jin for their constructive comments in improving the quality of this paper.

The research is supported by an Australian Government Research Training Program Scholarship. 


\section{References}

Berger, K. (2008). Developing person through the lifespan. New York: Worth Publishers.

Boxenbaum, E., \& Rouleau, L. (2011). New knowledge products as bricolage: Metaphors and scripts in organizational theory. Academy of Management Review, 36(2), 272-296.

Breakey, N., Ding, P., \& Lee, T. (2008). Impact of Chinese Outbound Tourism to Australia: Reviewing the Past; Implications for the Future. Current Issues in Tourism, 11(6), 587-603. doi:10.1080/13683500802475935

Brown, L. (2009). The transformative power of the international sojourn: An ethnographic study of the international student experience. Annals of Tourism Research, 36(3), 502521.

Buckley, R., McDonald, K., Duan, L., Sun, L., \& Chen, L. X. (2014). Chinese model for mass adventure tourism. Tourism Management, 44, 5-13.

doi:10.1016/j.tourman.2014.01.021

Cao, J. (2009). The analysis of tendency of transition from collectivism to individualism in China. Cross-Cultural Communication, 5(4), 42-50.

Chen, C. (2008). "Post-80s": the relationship between travel motivations and consumer behaviour. (Unpublished $\mathrm{PhD}$ thesis), Zhejiang University, Hangzhou.

Cheng, M., \& Wong, I. A. (2014). Tourism and Chinese Popular Nationalism. Journal of Tourism and Cultural Change, 12(4), 307-319. doi:10.1080/14766825.2014.914948

China Daily. (2010). Post-80s Generation. Retrieved from http://usa.chinadaily.com.cn/video/2010-12/23/content_11820151.htm

China Tourism Academy. (2014). Annual Report China Outbound Tourism Development 2014. Beijing: Beijing Eudcation Press.

Chung, J., Chen, C., \& Lin, Y. (2015). Cross-Strait tourism and generational cohorts. Journal of Travel Research, 55(6), 813-826. doi:10.1177/0047287515569775

Cockain, A. (2012). Young Chinese in Urban China. London: Tayor and Francis.

Egri, C. P., \& Ralston, D. A. (2004). Generation Cohorts and Personal Values: A Comparison of China and the United States. Organization Science, 15(2), 210-220. doi:10.1287/orsc. 1030.0048

Erikson, E. H. (1998). The Lift Cycle Completed. New York: Norton.

Featherstone, M. (2007). Consumer culture and postmodernism. Thousand Oaks: Sage.

Fong, V. L. (2007). Parent - Child Communication Problems and the Perceived Inadequacies of Chinese Only Children. Ethos, 35(1), 85-127. 
Gardiner, S. (2011). Generational Consumer Decision-making: A Study of Domestic Travel in Australia. (Doctoral Thesis), Griffith University, Glod Coast.

Gardiner, S., \& Kwek, A. (2017). Chinese participation in adventure tourism: A study of generation Y international students' perceptions. Journal of Travel Research, 56(4), 496-506.

Gu, Q., Wang, L., Sun, J. Y., \& Xu, Y. (2010). Understanding China's post-80 employees' work attitudes: an explorative study. Journal of Chinese Human Resources Management, 1(2), 74-94.

Guthrie, D. (2012). China and globalization: the social, economic and political transformation of Chinese society. London: Routledge.

Hsu, C. H., \& Huang, S. S. (2016). Reconfiguring Chinese cultural values and their tourism implications. Tourism Management, 54, 230-242.

Hulme, A. (2014). Iron rice bowls and plastic money: the push and pull of consumerism's rise in capitalist/communist China. In A. Humle (Ed.), The changing landscape of China'sconsumerism (pp. xxi-xxxi). Oxford: Elsevier.

Inglehart, R. (1997). Modernization and postmodernization: Cultural, economic, and political change in 43 societies. Princeton: Princeton University Press.

Jin, T., Lin, V. S., \& Hung, K. (2014). China's generation Y's expectation on outbound group package tour. Asia Pacific Journal of Tourism Research, 19(6), 617-644.

Jin, X., \& Wang, Y. (2016). Chinese outbound tourism research: A review. Journal of Travel Research, 55(4), 440-453. doi:10.1177/0047287515608504

Kelly, G. (2003). The Psychology of Personal Constructs: Volume Two: Clinical Diagnosis and Psychotherapy. London: Routledge.

Kelly, G. A. (1977). Personal construct theory and the psychotherapeutic interview. Cognitive therapy and research, 1(4), 355-362.

King, B., \& Gardiner, S. (2015). Chinese outbound student-tourists - developing a taste for independent travel. In X. Li (Ed.), Chinese Outbound Tourism 2.0 (pp. 320-334). Waretown: Apple Academic Press.

Lévi-Strauss, C. (1966). The savage mind. Chicago: University of Chicago Press.

Li, X. (2015). Rethinking Advanced Culture: a China-characterised briolage. In V. Perselli (Ed.), Education, theory and pedagogies of change in a global landscape (pp. 127149). Hampshire: Palgrave Macmillan.

Lian, H. (2014). The post-1980s generation in China: exploring its theoretical underpinning. Journal of Youth Studies, 17(7), 965-981.

Lin, N. (2011). Capitalism in China: A centrally managed capitalism (CMC) and its future. Management and Organization Review, 7(1), 63-96. 
Liu, D. (2015). Baling Hou: a photographic exploration of the Chinese post-80s generation in the urban cities of China. (Master thesis), AUT University, Auckland

Liu, F. (2011). Urban youth in China: Modernity, the Internet and the self. London: Routledge.

Liu, J., Li, M., \& Yue, X. (2010). Chinese social identity and inter-group relations: the influence of benevolent authority. In M. H. Bond (Ed.), The oxford handbook of Chinese psychology (pp. 579-598). Oxford: Oxford University Press.

Liu, J., Qu, H., Huang, D., Chen, G., Yue, X., Zhao, X., \& Liang, Z. (2014). The role of social capital in encouraging residents' pro-environmental behaviors in communitybased ecotourism. Tourism Management, 41, 190-201. doi:10.1016/j.tourman.2013.08.016

Milstein, T. (2005). Transformation abroad: Sojourning and the perceived enhancement of self-efficacy. International Journal of Intercultural Relations, 29(2), 217-238.

Morton, L. P. (2002). Targeting generation Y. Public Relations Quarterly, 47(2), 46.

National Bureau of Statistics China. (2010). 2010 Population Census. Beijing: China Statistics Press.

Ong, C.-E., \& du Cros, H. (2012). The Post-Mao gazes. Annals of Tourism Research, 39(2), 735-754. doi:10.1016/j.annals.2011.08.004

Palmer, J. (2012). The balinghou. Retrieved from https://aeon.co/essays/china-s-generationgap-has-never-yawned-wider

Pan, Y., Rowney, J. A., \& Peterson, M. F. (2012). The structure of Chinese cultural traditions: An empirical study of business employees in China. Management and Organization Review, 8(1), 77-95.

Parry, E., \& Urwin, P. (2011). Generational differences in work values: A review of theory and evidence. International Journal of Management Reviews, 13(1), 79-96.

Prayag, G., Disegna, M., Cohen, S. A., \& Yan, H. (2015). Segmenting markets by bagged clustering: Young Chinese travelers to Western Europe. Journal of Travel Research, 54(2), 234-250.

Procter, H. (2009). The construct. In R. Butler (Ed.), Reflections in personal construct theory (pp. 21-40). New Jersey: John Wiley \& Sons.

Renesas. (2013). The Post-80s, the driving power of China's Mammoth consumer market. Retrieved from http://am.renesas.com/edge_ol/global/09/index.jsp

Riley, N. (2004). China's population: new trends and challenges. Population Bulletin of Geography(59), 1-36. 
Rosen, S. (2009). Contemporary Chinese youth and the state. The Journal of Asian Studies, 68(2), 359-369. doi:10.1017/s0021911809000631

Roskin, M. (2012). Lumpy and sticky: ideational change over time. In B. Steele \& J. Acuff (Eds.), Theory and applications of the "generation" in international relations and politics. (pp. 229-246). New York: Palgrave Macmilian.

Ryan, C., Sun, M., Zhang, X., Li, F., Li, P., Gao, J., . . Hysin, L. (2016). Illustrations of Chinese tourism research. Tourism Management, 58, 229-234. doi:doi:10.1016/j.tourman.2016.03.006

Ryder, N. B. (1965). The cohort as a concept in the study of social change. American sociological review, 30(6), 843-861.

Sabet, D. (2011). Confucian or Communist, Post - Mao or Postmodern? Exploring the Narrative Identity Resources of Shanghai's Post - 80s Generation. Symbolic Interaction, 34(4), 536-551.

Sigurðsson, G. (2014). Frugralists, Anti-Consumers, and Prosumers: Chinese Philosophica Perspectives on Consumerism. In A. Hulme (Ed.), The Changing Landscape of China's Consumerism (pp. 125-149). Oxford: Elsevier.

Stanat, M. (2006). China's generation Y: Understanding the future leaders of the world's next superpower. Paramus: Homa \& Sekey Books.

Steele, B. (2012). Never trust anyone who remembers Jerry Rubin: the promise of generational conflict. In B. Steele \& J. Acuff (Eds.), Theory and applications of the "generation" in international relations and politics (pp. 25-46). New York: Palgrave Macmilian.

Strauss, W., \& Howe, N. (1991). Generations: The History of America's Future, 1584-2089. New York: Quill William Morrow.

Wang, C.-L., Chen, Z.-X., Chan, A. K., \& Zheng, Z.-C. (2000). The influence of hedonic values on consumer behaviors: an empirical investigation in China. Journal of Global Marketing, 14(1-2), 169-186.

Wang, Z. (2008). National humiliation, history education, and the politics of historical memory: Patriotic education campaign in China. International Studies Quarterly, 52(4), 783-806.

Weber, I. (2002). Shanghai baby: Negotiating youth self-identity in urban China. Social Identities, 8(2), 347-368.

Wei, S. (2009). The characteristics of Chinese Post-80s: the products of China's history. China Youth Studies, 7, 14-17.

Wen, X., Lehto, X. Y., Sydnor, S. B., \& Tang, C. H. (2014). Investigating Resort Attribute Preferences of Chinese Consumers: A Study of the Post-1980s and their Predecessors. 
Journal of China Tourism Research, 10(4), 448-474.

doi:10.1080/19388160.2014.959629

Winter, T. (2009). Asian tourism and the retreat of anglo-western centrism in tourism theory. Current Issues in Tourism, 12(1), 21-31. doi:10.1080/13683500802220695

World Tourism Cities Federation. (2014). Chinese citizen outbound tourism consumption. Retrieved from Beijing:

Wu, M., \& Pearce, P. (2014). Chinese recreational vehicle users in Australia: A netnographic study of tourist motivation. Tourism Management, 43, 22-35. doi:10.1016/j.tourman.2014.01.010

Wu, M., \& Pearce, P. (2016). Tourism Blogging Motivations Why Do Chinese Tourists Create Little "Lonely Planets"? Journal of Travel Research, 55(4), 537-549.

Wuest, B., Welkey, S., Mogab, J., \& Nicolas, K. (2008). Exploring consumer shopping preferences: Three generations. Journal of Family and Consumer Science, 100(1), 3137.

Wyn, J., \& Woodman, D. (2006). Generation, youth and social change in Australia. Journal of Youth Studies, 9(5), 495-514.

Yan, Y. (2010). The Chinese path to individualization. The British journal of sociology, 61(3), 489-512.

Yang, F. X., \& Lau, V. M.-C. (2015). "LuXurY” hotel loyalty-a comparison of Chinese Gen $\mathrm{X}$ and $\mathrm{Y}$ tourists to Macau. International Journal of Contemporary Hospitality Management, 27(7), 1685-1706.

$\mathrm{Yu}, \mathrm{X} .$, \& Xu, H. (2016). Ancient poetry in contemporary Chinese tourism. Tourism Management, 54, 393-403.

Zhang, G. (2015). Evolution of China's Policy of Outbound Tourism. In R. Li (Ed.), Chinese Outbound Tourism 2.0. Waretown: Apple Academic Press.

Zhang, P. (2009). Rethinking the impact of globalization and cultural identity in China. China Media Research, 5(2), 25-35.

Zhao, S. (2000). Chinese nationalism and its international orientations. Political Science Quarterly, 115(1), 1-33. 